THE LIFE STRATEGIES AND STRUCTURE OF POPULATIONS OF TORTRIX MOTHS (LEPIDOPTERA, TORTRICIDAE) IN ECOSYSTEMS OF THE EXCLUSION ZONE OF THE CHERNOBYL NUCLEAR POWER PLANT

\title{
Drozda Valentine
}

National University of Life and Environmental Sciences of Ukraine, Kyiv, Ukraine

\section{ЖИЗНЕННЫЕ СТРАТЕГИИ И СТРУКТУРА ПОПУЛЯЦИЙ ЛИСТОВЕРТОК (LEPIDOPTERA, TORTRICIDAE) В ЭКОСИСТЕMAX ЗОНЫ ОТЧУЖДЕНИЯ ЧАЭС}

\section{Дрозда Валентин}

Received 11.5. 2017

Revised 22. 5. 2017

Published 27. 11. 2017

The results of long-term researches about features of formation of life strategies and tactics of the population of tortrix moths in ecosystems of the exclusion zone of the Chernobyl nuclear power plant were presented. The factors are defining of character and specificity of life strategies of tortrix moths on an axis of $r$ - and K-continuum were analyzed. We collected and identified 38 of tortrix moths of garden and forest ecosystems of the exclusion zone. The physiological monitoring of phytophages suggested determination of the mass of pupae, fecundity, and content of lipids in caterpillars of rose tortrix moth. The structure and character of oogenesis of females of rose tortrix moth were researches in detail. The obtained data were compared with similar indicators of tortrix moths of collected in industrial gardens. The level of vitality of tortrix moths of collected in the exclusion zone exceeds significantly indicators of insects from industrial gardens. The expressed activity of native populations of entomophagous, which develops in the exclusion zone with an insignificant manifestation of entomopathogens was noted. The entomopathogens infected more intensively pupae of industrial gardens. This is due to with the physiological condition of tortrix moths. The indicative were materials of physiological monitoring of populations of tortrix moths, which selecting in ecosystems of the exclusion zone. On indicators of the mass of pupae, of the fecundity of females and content of lipids in caterpillars of rose tortrix moth was observed a significant excess of them in comparison with populations, which developing in industrial gardens. The ecological and trophic conditions of ecosystems of the exclusion zone are optimizing vital parameters of tortrix moths, which have developed here.

Keywords: populations of Tortrix moths; the exclusion zone; entomophagous; entomopathogens; viability; fecundity of females; content of lipids

\section{Введение}

Один из возможных путей относящихся к рассматриваемой проблеме с экологических позиций - разработка и научные обоснования способов биоиндикации антропогенных

\footnotetext{
*Corresponding author: Valentine Drozda, National University of Life and Environmental Sciences of Ukraine, Kyiv, Ukraine, $\triangle$ biomethod@quality.ua
} 
воздействий на природные экосистемы и составляющие их компоненты. Биоиндикация - это обнаружение и определение биологически и экологически значимых антропогенных нагрузок на основе реакций на нихживых организмов и их сообществ (Криволуцкий, 1994). В полной мере это относится ко всем видам антропогенных загрязнений. Особое место среди специфических загрязнений занимают все формы радиационных воздействий.

Импактный мониторинг - наблюдение воздействий на природные среды, биологические объекты и экосистемы от определенного источника эмиссий. В представленных материалах речь идет о специфическом воздействии последствий Чернобыльской аварии на характер развития популяций садовых листоверток. Излагаются материалы исследований, полученных на протяжении 20-ти лет.

Системы импактного мониторинга для популяций листоверток включают в себя средства наблюдения факторов воздействия и состояния природных сред и объектов, попадающих в зону влияния рассматриваемого объекта. К факторам воздействия, наблюдения которых проводятся в рамках импактного мониторинга, относятся: ионизирующте излучения, обусловленные радиоактивным загрязнением природной среды.

\section{Материалы и методы}

Проведена серия полевых и лабораторных исследований с отбором проб различных стадий развития листоверток из садов зоны отчуждения ЧАЭС. Использовались традиционные визуальные и инструментальные методы мониторинга (Васильев и Лившиц, 1984). В древесных насаждениях зоны отчуждения, а это яблони, груши, смородина черная, дуб обыкновенный, собирали яйцекладки, гусениц и куколок листоверток-филлофагов и ксиллофагов. Отлавливали имаго с использованием феромонных ловушек с синтетическими диспенсерами (Кузнецов, 1972; Кузнецов и Севастьянов, 1983). В лабораторных условиях определяли их жизнеспособность. При этом устанавливали смертность и причины гибели энтомофаги, энтомопатогены, другие факторы (Дорохова и др., 1989). Оценивали предикторы физиологического мониторинга (Дрозда, 2001, 2015). Определяли массу куколок, плодовитость и содержание липидов в гусеницах розанной листовертки (Archips rosana L.). Путем прижизненного препарирования гонад самок листоверток детально исследовали и характер оогенеза самок (Дрозда и Кочерга, 2015). Исследовали герминативную ткань гонад самок (Дрозда, 2001). Анализировали факторы, определяющие характер и специфику жизненных стратегий листоверток на оси r- и К-континуума (Macarthur and Wilson, 1963; Margalef, 1990).

\section{Результаты и их обсуждение}

В результате многолетнего изучения фауны листоверток садовых и лесных экосистем зоны отчуждения ЧАЭС выявлено 38 видов семейства Tortricidae. Из этого числа 22 вида экологически и трофически связаны с яблоней. Это розанная (Archips rosana L.), всеядная (A. podana Sc.), пестрозолотистая (A. xylosteana L.), боярышниковая (A. crataegana Hb.), листовертка-толстушка яркая (A. decretana Tr.), листовертка-толстушка сосновая (A. piceana L.), сетчатая (Adoxophyes orana F.R.), свинцовополосая (Ptycholoma lecheana L.), ранневесенняя (Tortricodes tortricella $\mathrm{Hb}$.), заморозковая (Exapate congelatella Cl.), дубовая палевая (Aleimma loeflingiana L.), дубовая зеленая (Tortrix viridana L.), плоская-дубовая (Acleris guercinana Z.), пугливая (Ancylis achatana Den. u. Schiff.), смородинная (Pandemis cerasana Hb.), ивовая кривоусая (P. hepatana Denn. et. Schiff.), дымчатая (Choristoneura diversana Hb.), подкоровая (Enarmonia formosana Sc.), почковая (Spilonota ocellana F.), плоская-сетчатая (Acleris rhombana Denn. et. Schiff.), плоская трехточечная (A. sparsana Denn. et. Schiff.), разноцветная плодовая (A. variegana Den. u. Schiff.), расписная (Apotomis linana Den. u. Schiff), лобезия обыкновенная (Lobesia religuana Hb.), изменчивая (Epinotia solangriana L.), почкоед-березовая, дубовая серая (Zeiraphera diniana Gn.), почковая осиновая (Gibberifera simplana F.), золотисто-бурая (Eucosmomorbha albersana Hb.), яблонная 
(Laspeyresia pononella L.), грушевая (L. pyrivora Danil.) и сливовая (Grapholitha funebrana Fr.) плодожорки. Видовую индентификацию проводили согласно наиболее авторитетным публикациям (Маркелова, 1957; Данилевский и Кузнецов, 1968; Костюк, 1968; Кузнецов, 1972; Лившиц, Петрушова, 1979; Николаева, 1999; Бичина и Гончаренко, 1981; Audemard, 1976).

Среди комплекса листоверток наиболее многочисленна группа филлофагов, объединяющая 22 вида. В насаждениях зоны отчуждения все они моноцикличны (Дрозда и Сагитов, 2015; Дрозда, 2016). Гусеницы питаются листьями и поверхностной тканью плодов. Часть из них зимует в стадии яйца (розанная, сетчатая, пестрозолотистая, разноцветная плодовая, боярышниковая, заморозковая). Остальные - в стадии гусениц. Детально исследована фенология листоверток в зоне отчуждения. В этом отношении нет принципиальной разницы в сроках развития листоверток в зоне отчуждения и за ее пределами (Дрозда и Ющенко, 2010; Дрозда и др., 2015).

Особенности их развития зависят от природно-климатических условий. В то же время детальное изучение экологических и физиологических характеристик листоверток в этих экосистемах позволили выявить особенности в индивидуальном и популяционном уровнях.

Материалы таблицы 1 иллюстрируют эти закономерности. Исследовались показатели жизненной стратегии розанной листовертки в экосистемах зоны отчуждения и за ее пределами, в промышленных садах.

Таблица 1 Экологические и физиологические характеристики популяций розанной листовертки

Table 1 The ecological and physiological characteristics of populations of rose tortrix moth

\begin{tabular}{|c|c|c|c|c|c|c|c|}
\hline \multirow{2}{*}{$\begin{array}{l}\text { Трофический ресурс } \\
\text { гусениц листоверток }\end{array}$} & \multicolumn{7}{|c|}{ Оценочные предикторы, смертность, \% } \\
\hline & 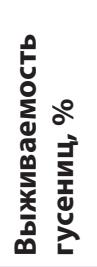 & 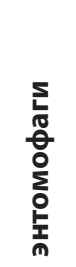 & 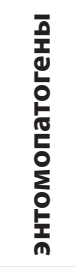 & 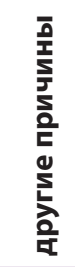 & 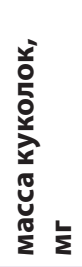 & 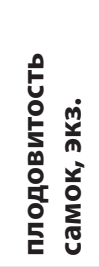 & 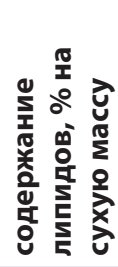 \\
\hline \multicolumn{8}{|c|}{ Зона отчуждения ЧАЭС } \\
\hline яблоня & 68,9 & 20,2 & 5,9 & 5,0 & 32,4 & 141,4 & 25,7 \\
\hline Груша & 59,6 & 24,4 & 13,0 & 3,0 & 29,2 & 130,7 & 21,8 \\
\hline Смородина черная & 63,7 & 27,6 & 3,4 & 5,3 & 30,7 & 134,6 & 23,8 \\
\hline Дуб обыкновенный & 70,2 & 19,8 & 3,6 & 6,4 & 33,1 & 144,5 & 25,4 \\
\hline \multicolumn{8}{|c|}{ Промышленные сады за пределами зоны отчуждения } \\
\hline яблоня & 59,2 & 11,3 & 14,6 & 17,9 & 28,9 & 128,3 & 21,2 \\
\hline Груша & 50,6 & 14,6 & 15,7 & 19,1 & 26,7 & 119,8 & 19,8 \\
\hline Смородина черная & 57,3 & 14,8 & 11,7 & 16,2 & 26,4 & 120,2 & 20,9 \\
\hline Дуб обыкновенный & 67,7 & 16,7 & 4,5 & 11,1 & 30,5 & 131,4 & 24,7 \\
\hline
\end{tabular}

Исходные данные - четыре различные трофические источники - деревесные и кустарниковые растения. Установлено, что уровень жизнеспособности популяций розанной листовертки, развивавшейся в экосистемах зоны отчуждения существенно превосходил показатели 
популяций, которые развивались за пределами зоны отчуждения. Основная причина смертности листоверток в период диапаузирования и зимовки - деятельность энтомофагов, энтомопатогенов и температурных аномалий. Существенным при этом было то, что уровень заражения энтомофагами разных стадий листоверток в экосистемах зоны отчуждения был в 1,5 - 2,0 раза выше, чем за пределами зоны. В то же время, энтомопатогены, в свою очередь, были причиной гибели значительной части популяций в промышленных садах. Это свидетельствует о том, что популяции розанной листовертки в зоне отчуждения характеризовались довольно высоким уровнем жизнеспособности. Их гусеницы и куколки характеризовались выраженными физиологическими и биохимическими показателями.

Достаточно сказать, что уровень содержания липидов в гусеницах розанной листовертки развивающихся в зоне ЧАЭС, на 10,1 - 21,2 \% превышал аналогичный показатель популяций листоверток промышленных садов. Существенно возрастала масса куколок листовертки в зоне ЧАЭС по сравнению с популяциями промышленных садов. Показатель превышения массы куколок увеличивался на 8,5 - 16,2 \%. Различия статистически достоверны. Как результат, самки, развивающиеся в экосистемах зоны отчуждения, характеризовались значительным репродуктивным потенциалом. Реальная их плодовитость на 9,1 - 12,2 \% превышала аналогичные показатели самок, чье развитие происходило в промышленных садах.

Проведенные исследования показали, что уровень заражения листоверток (яйца, гусеницы и куколки) энтомофагами, отобранных из зоны отчуждения, на 18,5 - 89,5 \% превосходил показатель плодовитости самок, отобранных из промышленных садов. В то же время, по показателям заражения разных стадий развития розанной листовертки различными энтомопатогенами, выявлена противоположная закономерность. Гусеницы и куколки листовертки, собранные в промышленных садах, были значительно более восприимчивы к действию нативных популяций энтомопатогенов. Объясняется этот феномен тем, что физиологически ослабленные популяции, а это те, которые развивались в промышленных садах, гораздо интенсивнее заражались энтомопатогенами. Разнообразные стрессовые факторы, преимущественно антропогенного характера - агротехнические приемы, обрезка деревьев и, главное, многократное использование пестицидов - факторы, дестабилизирующие популяционную структуру листоверток промышленных садов. Значительная их часть физиологически неполноценная и восприимчива к заболеваниям. В то же время популяции энтомофагов в зоне отчуждения имеют хороший трофический ресурс, в виде физиологически полноценных яиц, гусениц и куколок, заражая их при этом от 19,8 до 27,6 \%.

Однако, роль энтомофагов и энтомопатогенов в сравниваемых экосистемах, как природного регуляторного фактора, только модифицирующая. Это означает, что ни энтомофаги, ни энтомопатогены не способны существенно снизить общую численность листоверток. Трофический ресурс зоны отчуждения, безусловно близкий к оптимальному, по отношению к популяциям листоверток, чем тот, который формируется в промышленных садах.

Таким образом, многолетний мониторинг комплекса листоверток экосистем зоны отчуждения ЧАЭС свидетельствует об их динамической, волновой структуре, исключающий резкие вспышки их численности и внезапные затухания. Они лишь только утилизируют определенную часть фитомассы растений, которая восстанавливается компенсаторными механизмами экосистем.

\section{Выводы}

На основании многолетних исследований установлен видовой состав комплекса листоверток экосистем зоны отчуждения ЧАЭС. При этом выявлено 38 видов листоверток, из которых 22 вида экологически и трофически связанны с яблоней.

Установлено, что среди комплекса листоверток наиболее многочисленна группа филлофагов, объединяющая 22 вида.Похарактерусезонного развитиявсеонимоноцикличныеиподвержены 
преимущественно К-отбору. На основании результатов экологических и физиологических исследований показано, что популяция розанной листовертки, развивающаяся в экосистемах зоны отчуждения по всем тестовым характеристикам превосходят популяции розанной листовертки, которые развивались в промышленных садах.

Установлено также, что уровень заражения энтомофагами разных стадий листоверток в экосистемах зоны отчуждения был в 1,5 - 2,0 раза выше, чем за приделами зоны. Причиной смертности листоверток в промышленных садах были в основном энтомопатогены. Акцентируется внимание на том, что роль энтомофагов и энтомопатогенов в сравниваемых экосистемах, как природного регуляторного фактора, только модифицируящая.

\section{Литература}

Audemard, H. 1976. Etude demoecologigue de Carpocapsa pomonella L. en verger de pommiere de bosse. Vallee du Phone. Possibilites d'organisation dune lute integree. Tours (France), $365 \mathrm{p}$.

Mac Arthur, R.N., Wilson, E.D. 1963. An eguilibrium theory of insular zoogeography. Evolution, vol. 17, p. 373-378.

Margalef, R. 1990. La Biosfera entre la termodinamika y el juego. Barcelona: Omega, 236 p.

Бичина, Т.И., Гончаренко, Э.Г. 1981. Садоваые листовертки и их энтомофаги. Кишенев, Изд.: «Картя Молдавеняскэ», 150 с.

Васильев, В.П., Лившиц, И.3. 1984. Вредители плодовых культур. М.: Колос, 399 с.

Данилевский, А.С., Кузнецов, В.И. 1968. Листовертки Tortricidae, триба плодожорки Laspeyresiini. Фауна СССР. Л.: Изд. Наука, вып. 1, 635 с.

Дорохова, Г.И., Карелин, В.Д., Кирияк, И.Г. 1989. Полезная фауна плодового сада. Справочник. М.: Агропромиздат, 319 с.

Дрозда, В.Ф. 2001. Биоценотические обоснования интегрированной защиты плодовых насаждений от фитофагов в Лисостепи Украины: дисс. доктора с.-х. наук, Киев, 405 с.

Дрозда, В.Ф. 2015. Континуальная структура популяций яблонной плодожорки Laspeuresia pomonell L. (Lepidoptera, Tortricidae). Материалы Всероссийской конференции «Биогеосистемная экология и эволючионная биогеография», г. Новосибирск, с. 56-58.

Дрозда, В.Ф. 2016. Сукцессионные адаптации популяций яблонной плодожорки (Laspeyresia pomonella L.) в садах зоны отчуждения ЧАЭС. Biodiversity after the Chernobyl accident, Part 2, p. 74-78.

Дрозда, В.Ф., Кочерга, М.О. 2015. Концептуальні проблеми технологій захисту ягідників та алгоритм їх реалізації в системі органічного садівництва в Україні. Науковий журнал НУБіП України «Біоресурси та природокористування». Київ, т. 7, № 1-2, с. 67-76.

Дрозда, В.Ф., Сагитов, А.О. 2015. Характеристикижизненныхстратегий карпофагов в контекстезащиты садов в условиях Украины и Казахстана. Международная научная конференция «Инновационный экологическибезопасные технологии защиты растений». Казахстан, г. Алматы, с. 98-108.

Дрозда, В.Ф., Гойчук, А.Ф., Брайко, В.Б. 2015. Особливості технологій захисту лісопаркових насаджень від листокруток (Lepidoptera, Tortricidae). Міжнародна конференція «Екологічний стан лісотанів України», м. Харків, с. 103-104.

Дрозда, В.Ф., Ющенко, Л.П. 2010. Сливова плодожерка. Біологія, екологія, контроль чисельності. Київ, $152 \mathrm{c}$.

Костюк, Ю.А. 1968. Листовертки (Lepidoptera, Tortricidae) Украины. Видовой состав, распространение, особенности экологии: автореф. дисс. канд. биол. наук, Киев, 23 с.

Криволуцкий, Д.А. 1994. Почвенная фауна в экологическом контроле. М.: Наука. 272 с.

Кузнецов, В.И. 1972. Листовертки (Lepidoptera, Tortricidae) юга Дальнего Востока их экология и значение: автореф. дисс. доктора биол. наук, Л. 29 с. 
Кузнецов, Н.Н., Севастьянов, И.Н. 1983. Методические рекомендации по определению и учету численности плодовых листоверток. Ялта, Государственный Никитский ботсад, 25 с.

Лившиц, И.З., Петрушова, Н.И. 1979. Рекомендаци по учету численности вредителей яблони и прогнозу необходимости борьбы с ними. М.: Колос. 64 с.

Маркелова, В.П. 1957. Розанная, заморозковая и другие виды листоверток как вредители плодовоягодных культур и разработка химических мер борьбы с ними в условиях Ленинградской области: автореф. дисс. канд. С-х. наук. Л. 16 с.

Николаева, 3.В. 1992. Садовые листовертки северозаподной части Нечерноземной зоны РСФСР и биологическое обоснование мер борьбы с ними: автореф. дисс. канд. биол. наук. Ленинград Пушкин, 17 с. 